\title{
PERENCANAAN UNIT PRE-TREATMENT AIR LIMBAH INDUSTRI SPARE PART KENDARAAN BERMOTOR
}

\author{
The Design of Waste Water Pre-Treatment Unit of Automotive Component Industry \\ Oleh : \\ Setiyono \\ Pusat Teknologi Lingkungan, BPPT
}

\begin{abstract}
Abstrak
PT. Shei Tai Industrial merupakan salah satu industri yang memproduksi spare part kendaraan bermotor berupa blok mesin. Dengan adanya kegiatan produksi ini maka PT. Shei Tai Industrial akan menghasilkan limbah domestik dan limbah produksi yang banyak mengandung oli dan bahan kimia (pelarut) dengan konsentrasi yang cukup tinggi. Tingginya tingkat kandungan polutan limbah PT. Shei Tai Industrial, mengakibatkan limbah industri ini tidak dapat diterima secara langsung ke IPAL kawasan, sehingga PT. Shei Tai Industrial diwajibkan untuk membuat unit pre-treatment terlebih dahulu sebelum menyalurkan limbahnya ke IPAL kawasan. Untuk perencanaan unit pretreatment ini, PT. Shei Tai Industrial telah bekerja sama dengan para peneliti dari Pusat Teknologi Lingkungan untuk membuat disain perencanaan unit pre-treatment. Unit ini direncanakan dengan menggunakan teknologi proses fisika-kimia.
\end{abstract}

Kata kunci: Limbah Industri, Disain Pre-treatment air limbah.

\section{Abstract}

PT. Shei Tai Industrial, is one of the industries that produce motor vehicle spare parts such as the engine block. With these production activities, PT. Shei Tai Industrial will result in the production of domestic waste and waste that contains oil and chemicals (solvents) with a high enough concentration. The high levels of pollutant waste PT. Shei Tai Industrial, resulting in the waste industry cannot be accepted directly into the WWTP area, so PT. Shei Tai Industrial obliged to make a pre-treatment unit prior to the WWTP effluent channel region. For pre-treatment planning unit, PT. Shei Tai Industrial has teamed up with researchers from the Center for Environmental Technology to make planning pre-treatment unit design. This unit is planned by using physicalchemical process technology.

Keywords: Waste Industry, Design of wastewater pre-treatment.

\section{PENDAHULUAN}

\subsection{Latar Belakang}

PT. Shei Tai Industrial merupakan industri pendukung mesin kendaraan bermotor dan mesin mobil yang memproduksi spare part berupa blok mesin yang beralamat di Jl. Selayar, kawasan industri MM 2100, Cibitung, Bekasi, Jawa Barat. Kegiatan yang ada di industri ini adalah pembuatan blok mesin mobil dan peralatan mesin lainnya. Dalam melakukan aktivitasnya, industri ini banyak menggunakan air untuk kebutuhan domestik maupun untuk kebutuhan proses produksi, sehingga industri ini menghasilkan limbah cair meski dalam jumlah yang tidak terlalu besar. Secara garis besar, limbah cair yang dihasilkan oleh PT. Shei Tai Industrial berdasarkan karakteristiknya dapat dikelompokkan menjadi dua jenis, yaitu limbah domestik dan limbah produksi.

Karena PT. Shei Tai Industrial berlokasi di dalam kawasan industri, maka limbah yang dihasilkan harus diolah di instalasi pengolahan air limbah terpadu yang dikelola oleh pengelola kawasan. Namun demikian meski sudah ada IPAL terpadu, tetapi limbah tersebut harus sudah memenuhi standar tertentu yang ditetapkan oleh pihak pengelola, sehingga tidak semua limbah yang ada dapat diolah secara langsung ke IPAL terpadu.

Untuk itu maka pengelola kawasan membuat standar kualitas limbah yang boleh disalurkan ke IPAL terpadu. Jika ada perusahaan yang menghasilkan limbah di atas standar yang telah ditetapkan oleh pengelola IPAL, maka perusahaan tersebut diwajibkan untuk membuat unit pre-treatment untuk mengolah limbahnya terlebih dahulu sampai dapat terpenuhi standar limbah kawasan sebelum disalurkan ke IPAL kawasan.

\subsection{Tujuan dan Sasaran}

Kegiatan ini bertujuan untuk:

- Mengevaluasi limbah produksi PT. Shei Tai Industrial.

- Merencanakan sistem pengelolaan limbah.

- Mendisaint unit pre-treatment limbah produksi. 
Sasaran yang akan dicapai adalah terbangunya satu unit pre-treatment air limbah PT. Shei Tai Industrial.

\subsection{Metodologi}

Metodologi pelaksanaan kegiatan ini adalah sebagai berikut:

a. Survai lapangan, Observasi lapangan dan pengambilan data-data sekunder: (1). Jumlah limbah yang diolah per hari, (2). Karakteristik limbah yang dihasilkan.

b. Pengolahan data sekunder dan primer.

c. Analisa laboratorium.

d. Perencanaan teknis unit pre-treatment.

\section{PEMBAHASAN}

\subsection{Sumber Limbah Produksi PT. Shei Tai Industrial}

Sumber limbah produksi PT. Shei Tai Industrial berasal dari unit proses produksi blok mesin dan pencucian produk blok. Limbah ini banyak mengandung bahan kimia coolant yang digunakan pada proses screping blok mesin hasil pengepresan. Disamping itu limbah ini juga mengandung serpihan logam hasil screping blok mesin.

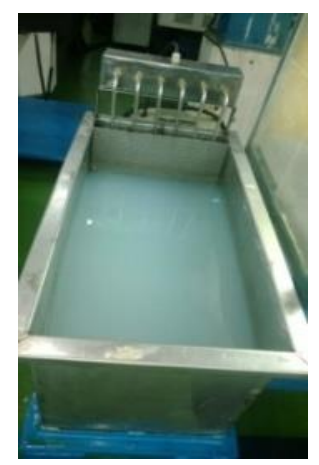

Gambar 1. Foto limbah produksi.

Berdasarkan hasil evaluasi di lapangan, dan diskusi yang dilakukan bersama dengan pihak menajemen dan bagian proses produksi, maka penggunaan air untuk proses produksi rata-rata 1,5 $\mathrm{m}^{3}$ /hari. PT. Shei Tai Industrial juga merencanakan untuk menambah line proses produksi dan meningkatkan proses produksinya, sehingga berdasarkan hasil perhitungan bersama dan kesepakatan, maka unit ini direncanakan dengan kapasitas sebesar $5 \mathrm{~m}^{3} /$ hari.

\subsection{Karakteristik Limbah Produksi PT. Shei Tai}

Industrial.

Hasil analisa air limbah produksi yang yang dilakukan pada tanggal 24 Maret 2014 terlihat seperti pada Tabel 1 (Envirotekno Karya Mandiri, 2014).
Kandungan limbah produksi adalah oli danpolutan pencemar berupa senyawa-senyawa kimia pelarut dan juga terdapat bahan-bahan serpihan logam. Berdasarkan hasil analisa perbandingan COD : BOD yang mencapai 2.264 : 792 dapat diperkirakan bahwa unit pre-treatment ini akan lebih baik jika menggunakan proses fisika-kimia.

\subsection{Pengelolaan Limbah Saat Ini}

Saat ini air limbah proses produksi ini dikelola dengan sarana grease trap. Di grease trap ini berfungsi untuk memisahkan oli secara gravitasi, dan dilakukan secara bertingkat. Kemudian outlet dari grease trap ini ditampung di drum-drum untuk dikirim ke perusahaan pengolah limbah. Diagram alir sistem pengelolaan limbah dan foto grease trap dapat dilihat seperti pada pada Gambar 3. (Envirotekno Karya Mandiri, 2014).

Air limbah produksi dikelola dengan sarana grease trap yang dilengkapi dengan bak pengendap. Di sini padatan yang ada diendapkan dan oli yang terbawa dipisahkan di grease trap. Padatan dan oli yang sudah tertahan di grease trap secara periodik diambil secara manual dengan tenaga manusia. Sedangkan outlet air limbah ini dikumpulkan di dalam drum-drum kemudian dikirim ke perusahaan pengolahan limbah karena kualitasnya masih belum memenuhi standar limbah kawasan.

Tabel 1. Karakteristik air limbah produksi PT. Shei Tai Industrial.

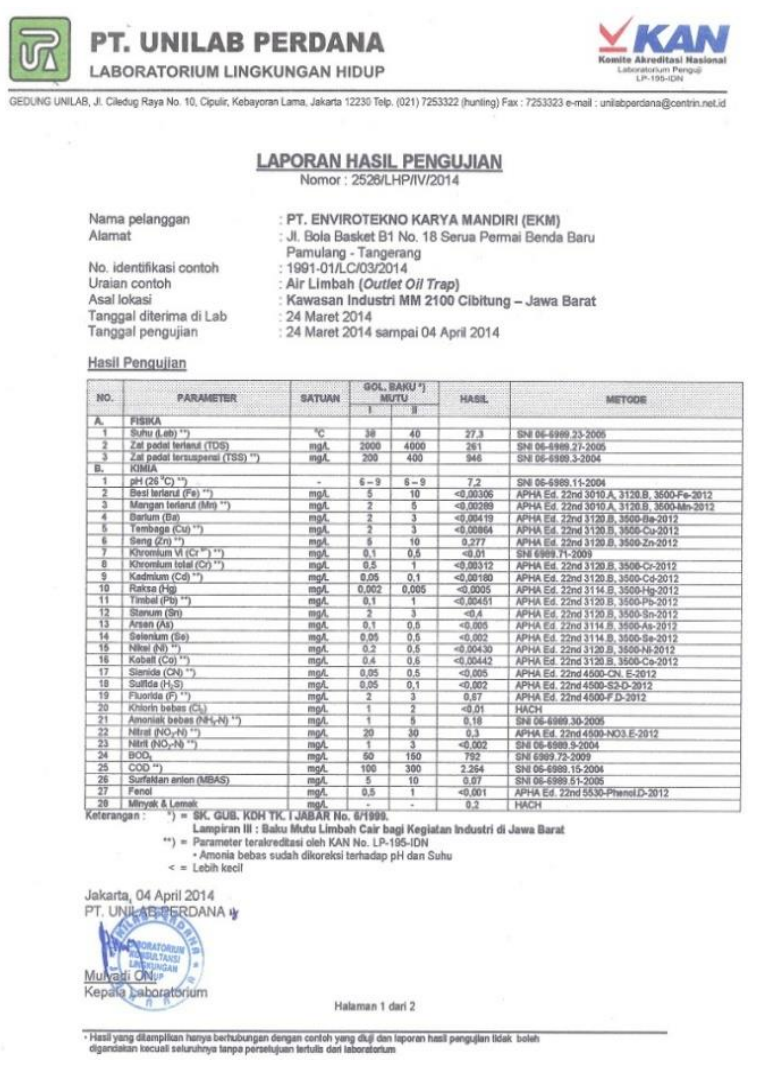




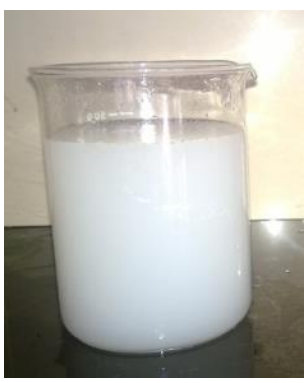

Gambar 2. Foto Kondisi Fisik Limbah Produksi.

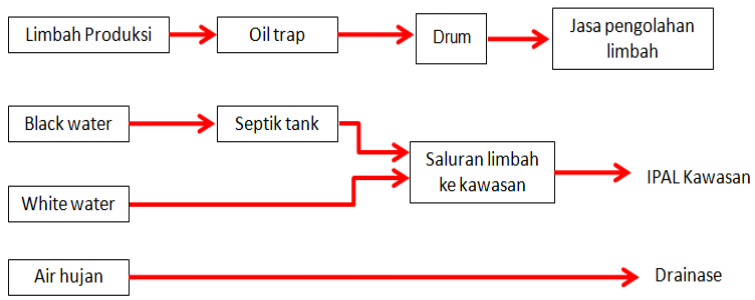

Gambar 3. Diagram alir pengelolaan limbah produksi.

\subsection{Perbaikan Sistem Pengelolaan Limbah.}

Karena PT. Shei Tai Industrial berada di dalam kawasan industri, maka dalam mengelola limbahnya perusahaan ini harus mengikuti peraturan yang ada di dalam kawasan, yang mana semua limbah cair yang dihasilkan harus dikirim untuk diolah di dalam IPAL kawasan dan dengan kualitas limbah yang harus memenuhi standar limbah kawasan seperti tabel 2, (Pengelola Kawasan MM 2100).

Tabel 2. Standar Kualitas Air Limbah Kawasan Industri MM 2100 Cibitubung, Bekasi.

\begin{tabular}{|c|c|c|c|c|}
\hline No & PARAMETER & Unit & Max & $\begin{array}{c}\text { West Java } \\
\text { (Governor) } 1999\end{array}$ \\
\hline 1 & Physical & & & \\
\hline 1 & Temperatur & ${ }^{\circ} \mathrm{C}$ & 40 & 38 \\
\hline 2 & Dissolved Solid & $\mathrm{mg} / \mathrm{l}$ & 4.000 & 2000 \\
\hline 3 & Suspended Solid & $\mathrm{mg} / \mathrm{l}$ & 400 & 200 \\
\hline II & Chemical & & & \\
\hline 1 & $\mathrm{pH}$ & & $5,5 \sim 9,5$ & $6,0 \sim 9,0$ \\
\hline 2 & Iron $(\mathrm{Fe})$ & $\mathrm{mg} / \mathrm{l}$ & 10 & 5 \\
\hline 3 & Manganese (Mn) & $\mathrm{mg} / \mathrm{l}$ & 0,2 & 0,1 \\
\hline 4 & Barium $(\mathrm{Ba})$ & $\mathrm{mg} / \mathrm{l}$ & 1 & 0,5 \\
\hline 5 & Copper (Cu) & $\mathrm{mg} / \mathrm{l}$ & 4 & 2 \\
\hline 8 & Zinc $(Z n)$ & $\mathrm{mg} / \mathrm{l}$ & 10 & 5 \\
\hline 7 & Chrom Hexavalen $\left(\mathrm{Cr}^{\circ}\right)$ & $\mathrm{mg} / \mathrm{l}$ & 0,2 & 0,1 \\
\hline 8 & Chrom Total $(\mathrm{Cr})$ & $\mathrm{mg} / \mathrm{l}$ & 1 & 0,5 \\
\hline 9 & Cadmium (Cd) & $\mathrm{mg} / \mathrm{l}$ & 0,1 & 0,05 \\
\hline 10 & Mercury $(\mathrm{Hg})$ & $\mathrm{mg} / \mathrm{l}$ & 0,004 & 0,002 \\
\hline 11 & Lead $(\mathrm{Pb})$ & $\mathrm{mg} / \mathrm{l}$ & 0,2 & 0,1 \\
\hline 12 & $\operatorname{Tin}(\mathrm{Sn})$ & $\mathrm{mg} / \mathrm{l}$ & 4 & 2 \\
\hline 13 & Arsenic (As) & $\mathrm{mg} / \mathrm{l}$ & 0,2 & 0.1 \\
\hline 14 & Selenium(Se) & $\mathrm{mg} / \mathrm{l}$ & 0.1 & 0,05 \\
\hline 15 & Nidkel (Ni & $\mathrm{mg} / \mathrm{l}$ & 0,4 & 0,2 \\
\hline 16 & Cobalt (Co) & $\mathrm{mg} / \mathrm{l}$ & 0,8 & 0.4 \\
\hline 17 & Cyanide (CN) & $\mathrm{mg} / \mathrm{l}$ & 0.1 & 0,05 \\
\hline 18 & Sulfide (H2S) & $\mathrm{mg} / \mathrm{l}$ & 0,1 & 0,05 \\
\hline 19 & Flouride (F) & $\mathrm{mg} / \mathrm{s}$ & 4 & 2 \\
\hline 20 & Free Chlorine $(\mathrm{Cl} 2)$ & $\mathrm{mg} / \mathrm{l}$ & 2 & 1 \\
\hline 21 & Free Ammoniac (NH3-N) & $\mathrm{mg} / \mathrm{l}$ & 2 & 1 \\
\hline 22 & Nit ste $(\mathrm{NO}-\mathrm{N})$ & $\mathrm{mg} / \mathrm{l}$ & 40 & 20 \\
\hline 23 & Nit ite (NO2-N) & $\mathrm{mg} / \mathrm{s}$ & 2 & 1 \\
\hline 24 & $B O D 5$ & $\mathrm{mg} / \mathrm{l}$ & 200 & 50 \\
\hline 25 & $\mathrm{COD}, \mathrm{Cr}$ & $\mathrm{mg} / \mathrm{s}$ & 400 & 100 \\
\hline 26 & Surfactant Anionic as MBAS & $\mathrm{mg} / \mathrm{s}$ & 10 & 5 \\
\hline \multirow{3}{*}{$\begin{array}{l}27 \\
28 \\
29\end{array}$} & \multirow{3}{*}{$\begin{array}{l}\text { Phenol Compou } \\
\text { Oil and Fats } \\
\text { Radio Is otop (1) }\end{array}$} & $\mathrm{mg} / \mathrm{l}$ & 1 & 0,5 \\
\hline & & $\mathrm{mg} / \mathrm{h}$ & 10 & 5 \\
\hline & & \multicolumn{3}{|c|}{$\begin{array}{l}\text { Accordin } \\
\text { Power }\end{array}$} \\
\hline
\end{tabular}

Note : According to Degree of Governor of West Java No. 6/1999, Dated on March 13, 1999.
Secara detail, sistem pengelolaan limbah di dalam kawasan MM 2100 ditunjukkan pada Gambar 4 (Setiyono, 2014).

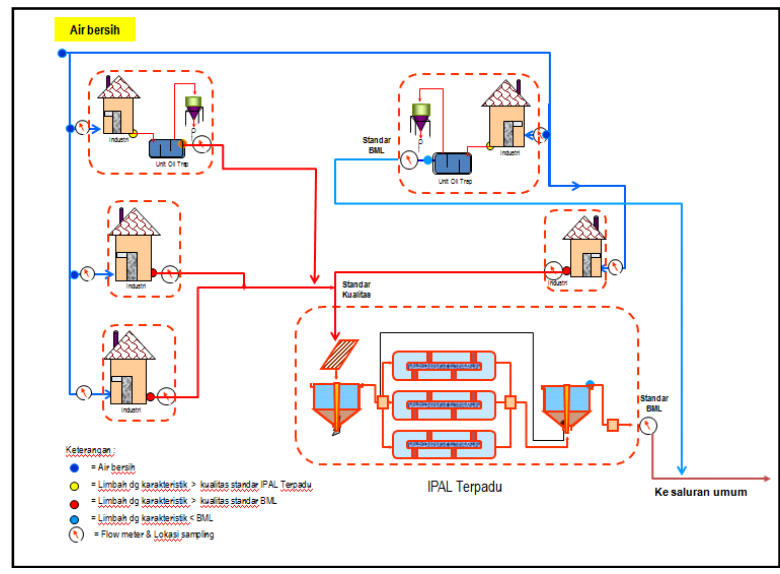

Gambar 4. Diagram Alir Sistem Pengelolaan Limbah Di Kawasan Industri MM 2100.

Diagram alir sistem pengelolaan limbah di dalam perusahaan yang direncanakan dapat dilihat seperti pada Gambar 5. Pengelolaan air limbah produksi ini dilakukan mulai dari sumbernya, yang mana air limbah produksi disalurkan terlebih dahulu masuk ke oil trap yang telah diperbaiki. Setelah melalui oil trap, limbah ini disalurkan ke bak ekualisasi, terus dilakukan proses koagulasi-flokulasi dan sedimentasi. Kemudian endapan yang terbentuk ditampung ke dalam drum untuk dikirim ke perusahaan pengolah limbah B-3, sedangkan filtratnya yang sudah memenuhi standar kualitas limbah kawasan seperti tertera dalam tabel 2 dikirim ke IPAL kawasan.

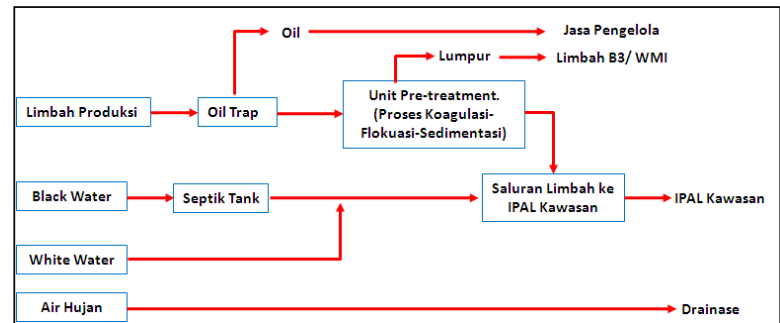

Gambar 5. Diagram Alir Perbaikan Sistem

Pengelolaan Limbah PT. Shei Tai Industrial.

\subsection{Teknologi pre-treatment air limbah produksi PT. Shei Tai Industrial}

Pengolahan pre-treatment air limbah PT. Shei Tai Industrialbertujuan untuk menurunkan kadar bahan polutan limbah agar limbah ini dapat memenuhi standar kualitas limbah kawasan. Karena kandungan utama limbah PT.Shei Tai Industrial ini berupa oli, bahan kimia coolant dan padatan anorganik seperti serpihan logam, maka proses 
pengolahan yang dipilih adalah dengan proses fisika dan kimia. Jika dengan teknologi ini kualitas limbah yang dihasilkan sudah memenuhi standar kualitas limbah kawasan, maka outlet limbah ini akan langsung disalurkan ke IPAL kawasan, namun jika masih belum memenuhi standar maka proses pengolahan akan dilanjutkan dengan proses biologi. Secara detail diagram alir proses pengolahan yang akan diterapkan adalah sebagai berikut (Envirotekno Karya Mandiri, 2014).

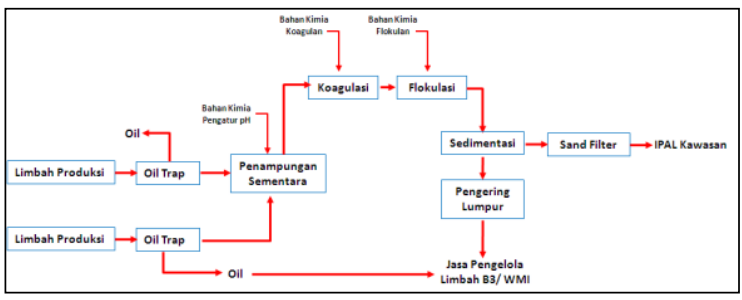

Gambar 6. Diagram Alir Proses Pengolahan Limbah Produksi PT. Shei Tai Industrial.

\subsubsection{Proses Screening (Penyaringan)}

Di dalam proses pengolahan air limbah, screening atau saringan dilakukan pada tahap paling awal. Saringan untuk penggunaan umum (general porpose screen) dapat digunakan untuk memisahkan bermacam-macam benda padat yang ada di dalam air limbah yang utama adalah serpihan logam dari blok mesin yang diproduksi.

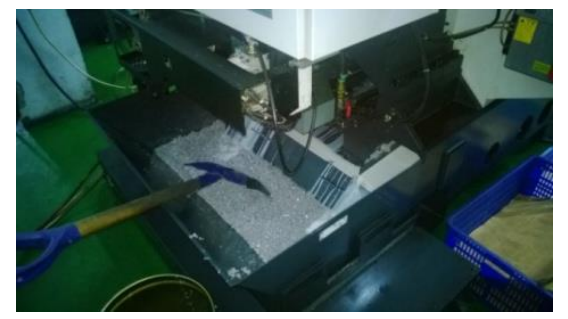

Gambar 7. Sreen Untuk Screping Serpihan Logam.

Serpihan logam ini harus dipisahkan di tahap paling awal pada proses pengelolaan limbah. Bendabenda tersebut jika tidak dipisahkan dapat menyebabkan penyumbatan pada pipa saluran air limbah, kerusakan pada sistem pemompaan dan unit peralatan lainnya karena sifatnya yang keras dan tajam.

\subsubsection{Unit Pemisah Pasir (Grit Removal) dan Pemisah Oli (Oil Trap)}

Di dalam proses pengolahan air limbah, pasir, kerikil halus, dan juga benda-benda lain misalnya serpihan logam yang lolos dari screen dan lain lain harus dipisahkan terlebih dahulu. Hal ini dilakukan untuk:
1) Melindungi kerusakan pada peralatan mekanik seperti pompa, flow meter dll, agar tidak terjadi abrasi atau kebuntuan.

2) Untuk menjaga atau mencegah kebuntuan di dalam sistem perpipaan dan terjadinya pengendapan di dalam saluran.

3) Untuk mencegah pengerakan (cementing) di dasar bak pengolahan proses berikutnya.

4) Untuk mengurangi atau menghilangkan akumulasi dari material inert yang tidak dapat terurai di dalam bak aerasi atau reaktor biologis serta bak pengolah lumpur yang akan mengakibatkan kerugian volume (loss of usable volume).

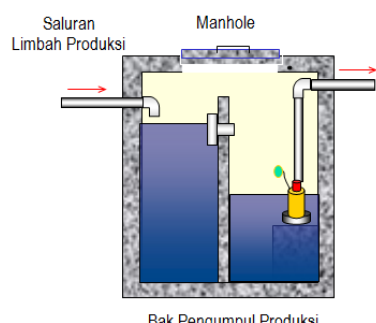

Gambar 8. Bak pemisah pasir

Bak pemisah pasir ini juga didesain sebagai bak pemisah oli dan minyak yang berfungsi untuk memisahkan oli dan senyawa hidrokarbon lainnya di dalam proses emulsi mekanik, karena kandungan minyak ini dapat mengganggu proses koagulasiflokulasi. Air yang dihasilkan harus bebas oli dan minyak, sehingga proses koagulasi-flokulasi dapat berjalan dengan sempurna dan pemakaian bahan kimia dapat efektif dan effisien. Pemisahan oli/minyak dilakukan tanpa adanya penambahan bahan kimia, tetapi hanya dilakukan dengan cara gravitasi alami, dimana butiran oli/minyak naik keatas karena berat jenisnya (specific gravity). Oli yang terkandung di dalam limbah relatif mudah untuk dipisahkan dan teknologinya relatif lebih sederhana namun dapat diterapkan dengan efektif di sini.

Berdasarkan hasil percobaan pemisahan oli dari limbah secara laboratorium, maka oli yang terkandung dapat terpisah secara sempurna dalam waktu kurang dari 45 menit, sedangkan proses produksi diasumsikan berjalan selama 12 jam, sehingga debit limbah sebesar $5 \mathrm{~m}^{3} / 12$ jam $=416,67$ liter $\mathrm{m}^{3} / \mathrm{jam}$. Untuk keamanan proses, maka waktu tinggal dibuat dalam waktu 2 jam dan bak dibuat dengan sistem bertingkat (skat). Dengan demikian maka volume bak yang diperlukan 416,67 It $\times 2$ jam $=$ 833 It $\infty 1 \mathrm{~m}^{3}$. Disain yang ada :

$$
\begin{aligned}
& \text { Volume Efektif Oil Trap: } \\
& \begin{aligned}
\mathrm{R}-1=70 \times 75 \times 90 & =472,5 \\
\mathrm{R}-2=60 \times 75 \times 80 & =360,0 \\
\mathrm{R}-3=60 \times 75 \times 70 & =315,0 \\
\text { TOTAL } & =1.147,5 \mathrm{It} . \\
& =1,147 \mathrm{~m}^{3} .
\end{aligned}
\end{aligned}
$$




\subsubsection{Proses Pengaturan pH}

Proses pengaturan $\mathrm{pH}$ bertujuan untuk mengontrol $\mathrm{pH}$ limbah agar sesuai dengan kondisi yang diinginkan, dengan cara penambahan bahan kimia asam/basa. Hal ini dimaksudkan agar proses pengolahan selanjutnya dapat berjalan dengan baik. Bahan kimia yang umum digunakan adalah asam sulfat $\left(\mathrm{H}_{2} \mathrm{SO}_{4}\right)$ atau asam khlorida $(\mathrm{HCl})$ untuk menetralkan air limbah yang bersifat alkali. Sedangkan untuk zat alkali yang banyak digunakan antara lain : soda ash atau soda abu $\left(\mathrm{NaHCO}_{3}\right)$, Kapur tohor $(\mathrm{CaO}), \mathrm{Ca}(\mathrm{OH})_{2}, \mathrm{CaCO}_{3}$, natrium hidroksida $(\mathrm{NaOH})$. Berdasarkan hasil analisa, air limbah produksi PT. Shei Tai Industrial dalam kondisi netral sehingga untuk proses koagulai-flokulasi perlu merubah $\mathrm{pH}$ agar proses dapat berjalan dengan baik. Karena proses pengolahan yang dilakukan secara bact, sehingga diperlukan proses pengontrolan $\mathrm{pH}$ secara manual dengan mudah.

\subsubsection{Proses Koagulasi-Flokuasi}

Koagulasi adalah proses destabilisasi koloid dengan penambahan senyawa kimia yang disebut zat koagulan. Flokulasi adalah proses penggumpalan (agglomeration) dari koloid yang tidak stabil menjadi gumpalan partikel halus (micro-floc), dan selanjutnya menjadi gumpalan patikel yang lebih besar dan dapat diendapkan dengan cepat. Senyawa kimia lain yang diberikan agar pembentukan flok menjadi lebih cepat atau lebih stabil dinamakan flokulan atau zat pembantu flokulasi (flocculant aid).

Untuk menghilangkan partikel-partikel yang sangat halus maupun koloid yang sulit mengendap diperlukan adanya bantuan bahan kimia untuk proses pengendapan. Sehingga tujuan dari penambahan bahan kimia ini adalah agar partikel-partikel yang sukar mengendap tadi menggumpal menjadi besar dan berat sehingga kecepatan pengendapannya lebih besar. Pada umumnya proses ini menggunakan dua jenis bahan kimia, yaitu bahan kimia koagulan dan flokulan.

Koagulan adalah bahan kimia yang berfungsi untuk menggumpalkan partikel-partikel padat tersuspensi, zat warna, koloid dan lain-lain agar membentuk gumpalan partikel. Flokulant adalah bahan kimia yang berfungsi untuk pembentukan flokflok agar menjadi besar dan stabil sehingga dapat diendapkan dengan mudah atau disaring. Untuk proses pengendapan dan penyaringan maka partikelpartikel kotoran halus maupun koloid yang ada dalam air baku harus digumpalkan menjadi flok-flok yang cukup besar dan kuat. Bahan koagulan dan flokulan dipilih berdasarkan karakteristis air limbah yang akan diolah dengan melakukan pengujian dengan alat jar test di laboratorium seperti pada gambar 9 di bawah ini.

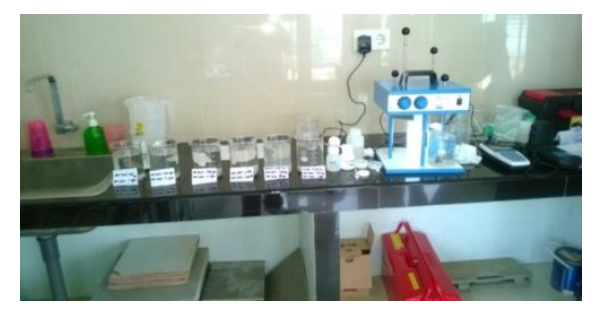

Gambar 9. Penggunaan Jar Test Limbah PT. Shei Tai Industrial

Penelitian dengan alat jar test diperlukan untuk memilih jenis bahan koagulan dan flokulan yang tepat sesuai dengan karakteristik air limbah yang akan diolah, dan untuk mengetahui dosis pemakaiannya serta kondisi $\mathrm{pH}$ optimumnya. Pemilihan bahan-bahan kimia ini, disamping memperhatikan kwalitas air olahan, juga harus dipertimbangkan faktor harga bahan dan jumlah endapan (sludge) yang akan dihasilkannya. Hasil jar test limbah PT. Shei Tai Industrial dapat dilihat seperti pada gambar 10 dan tabel 3 dan 4 (Envirotekno Karya Mandiri, 2014).

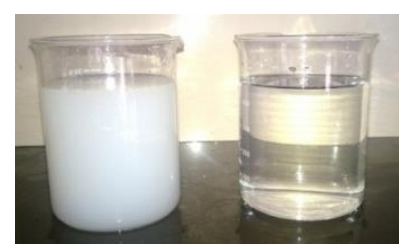

Gambar 10. Foto Hasil Jar Test Limbah PT. Shei Tai

Tabel 3. Hasil Jar Test

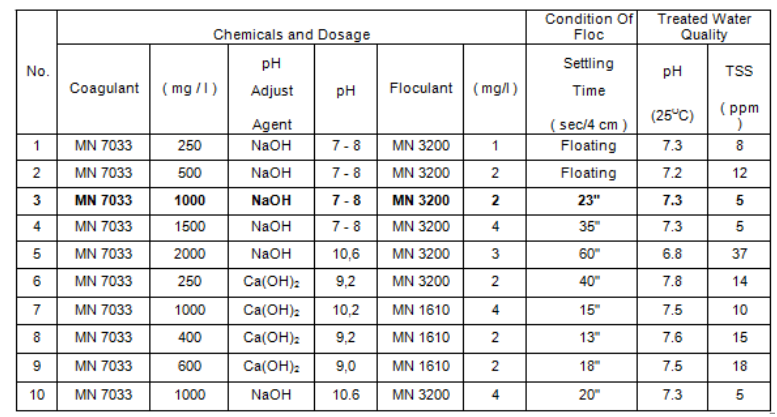

Berdasarkan hasil analisa kualitas filtrat limbah hasil koagulasi-flokulasi PT.Shei Tai Industrial, maka semua parameter yang ada masih di bawah standar limbah yang diijinkan untuk disalurkan ke IPAL kawasan MM 2100. Dengan demikian, unit pretreatment ini cukup dilakukan dengan proses screening, pengendapan, pemisahan oli, koagulasiflokulasi dan diakhiri dengan proses sedimentasi.

\subsubsection{Reaktor Koagulasi - Flokulasi}

Reaktor koagulasi-flokulasi dilengkapi dengan alat pengaduk/agitator agar bahan kimia yang dibubuhkan dapat bercampur dengan air limbah 
secara cepat dan merata. Oleh karena kecepatan pengadukan dan waktu tinggal yang akan memberikan kesempatan kontak antara bahan kimia dengan partikel padatan di dalam limbah diberikan secukupnya agar dapat terbentuk butiran endapan yang dapat berkembang menjadi flok-flok berukuran besar dan stabil yang mudah diendapkan. Untuk itu diperlukan pengadukan yang cepat guna pembentukan bibit endapan dan pengadukan lambat untuk proses pertumbuhan flok.

Tabel 4. Hasil Analisa Kualitas Limbah Setelah Proses Koagulasi-Flokulasi Dibandingkan Dengan Standar Kualitas Limbah Kawasan MM 2100.

\begin{tabular}{|c|c|c|c|c|}
\hline No & PARAMETER & Unit & $\begin{array}{c}\operatorname{Max} \\
\text { MM } 2100 \\
\end{array}$ & Hasil Analisa \\
\hline 1 & Physical & & & \\
\hline 1 & Temperatur & ${ }^{\circ} \mathrm{C}$ & 40 & 27,3 \\
\hline 2 & Dissolved Solid & $\mathrm{mg} / \mathrm{l}$ & 4.000 & 608 \\
\hline 3 & Suspended Solid & $\mathrm{mg} / \mathrm{l}$ & 400 & 17 \\
\hline II & Chemical & & & \\
\hline 1 & $\mathrm{pH}$ & & $5,5 \sim 9,5$ & 7.6 \\
\hline 2 & Iron $(\mathrm{Fe})$ & $\mathrm{mg} / \mathrm{l}$ & 10 & $<0,00308$ \\
\hline 3 & Manganese (Mn) & $\mathrm{mg} / \mathrm{l}$ & 0,2 & $<0,00289$ \\
\hline 4 & Barium $(\mathrm{Ba})$ & $\mathrm{mg} / \mathrm{l}$ & 1 & $<0,00419$ \\
\hline 5 & Copper (Cu) & $\mathrm{mg} / \mathrm{l}$ & 4 & $<0,00864$ \\
\hline 6 & Zinc $(Z n)$ & $\mathrm{mg} / \mathrm{l}$ & 10 & $<0,00851$ \\
\hline 7 & Chrom Hexavalen $\left(\mathrm{Cr}^{*}\right)$ & $\mathrm{mg} / \mathrm{l}$ & 0,2 & $<0,01$ \\
\hline 8 & Chrom Total $(\mathrm{Cr})$ & $\mathrm{mg} / \mathrm{l}$ & 1 & $<0,00312$ \\
\hline 9 & Cadmium (Cd) & $\mathrm{mg} / \mathrm{l}$ & 0,1 & $<0,00180$ \\
\hline 10 & Mercury $(\mathrm{Hg})$ & $\mathrm{mg} / \mathrm{l}$ & 0,004 & $<0,0005$ \\
\hline 11 & Lead $(\mathrm{Pb})$ & $\mathrm{mg} /$ & 0,2 & $<0,00451$ \\
\hline 12 & $\operatorname{Tin}(\mathrm{Sn})$ & $\mathrm{ma} /$ & 4 & $<0,4$ \\
\hline 13 & Arsenic (As) & $\mathrm{mg} /$ & 0,2 & $<0,005$ \\
\hline 14 & Selenium (Se) & $\mathrm{mg} /$ & 0.1 & $<0,002$ \\
\hline 15 & Nidkel (Ni & $\mathrm{mg} / 1$ & 0.4 & $<0,00430$ \\
\hline 16 & Cobalt $(\mathrm{Co})$ & $\mathrm{mg} /$ & 0,8 & $<0,00442$ \\
\hline 17 & Cyanide $(\mathrm{CN})$ & $\mathrm{mg} / 1$ & 0.1 & $<0,005$ \\
\hline 18 & Sulfide (H2S) & $\mathrm{mg} / 1$ & 0.1 & $<0,002$ \\
\hline 19 & Flouride (F) & $\mathrm{mg} /$ & 4 & 0,30 \\
\hline 20 & Free Chlorine $(\mathrm{Cl} 2)$ & $\mathrm{mg} /$ & 2 & $<0,01$ \\
\hline 21 & Free Ammoniac(NH3-N) & $\mathrm{mg} /$ & 2 & 0,58 \\
\hline 22 & Nit ate (NO3-N) & $\mathrm{mg} / \mathrm{l}$ & 40 & 0,2 \\
\hline 23 & Nit ite $(\mathrm{NO2}-\mathrm{N})$ & $\mathrm{mg} / 1$ & 2 & 0,018 \\
\hline 24 & BOD 5 & $\mathrm{mg} /$ & 200 & 64 \\
\hline 25 & $\mathrm{COD}, \mathrm{Cr}$ & $\mathrm{mg} / 1$ & 400 & 185 \\
\hline 28 & Surfactant Anionic as MBAS & $\mathrm{mg} / \mathrm{l}$ & 10 & 0,08 \\
\hline 27 & Phenol Compound & mg/ & 1 & $<0,001$ \\
\hline 28 & Oil and Fats & $\mathrm{mg} / 1$ & 10 & 2,3 \\
\hline 29 & Radio Isctop@ & & & \\
\hline
\end{tabular}

Sumber : (Envirotekno Karya Mandiri, 2014).

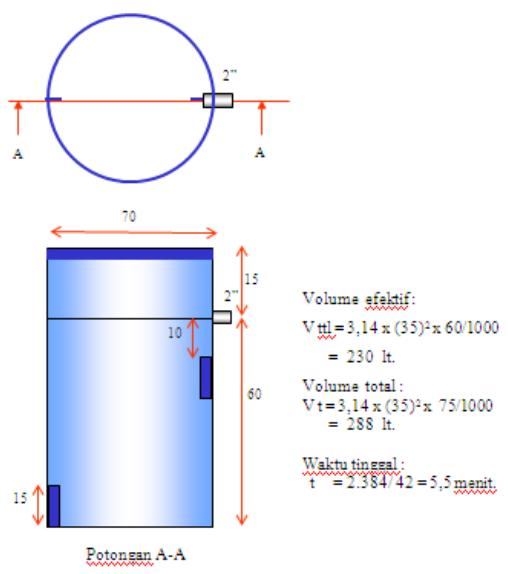

Gambar 11. Gambar Desain Reaktor Koagulasi.
Spesifikasi di dalam proses koagulasi-flokulasi tersebut sebagai berikut :

1) Kapasitas proses $=5 \mathrm{~m}^{3} / 2$ jam $=42 \mathrm{lt} / \mathrm{mnt}$.

2) Waktu tinggal proses koagulasi $=5$ menit.

3) Waktu tinggal proses flokulasi $=10$ menit.

4) Rotasi proses koagulasi $=100 \mathrm{rpm}$.

5) Rotasi proses flokulasi $=30 \mathrm{rpm}$.

6) Volume reaktor koagulasi :

7) Volume reaktor flokulasi :

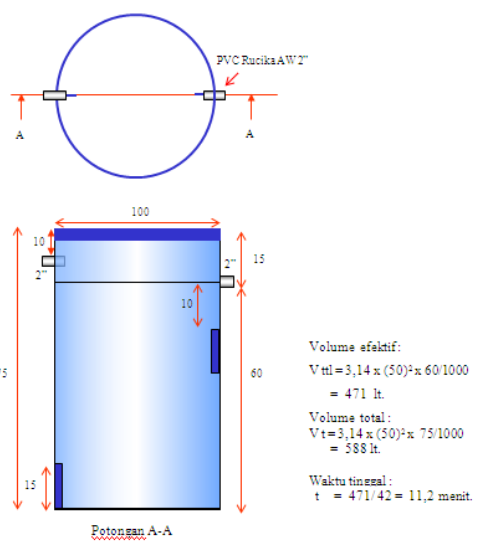

Gambar 12. Gambar Desain Reaktor Flokulasi.

\subsubsection{Sedimentasi atau Pengendapan}

Sedimentasi adalah suatu unit operasi untuk menghilangkan flok yang terbentuk pada proses koagulasi-flokulasi secara gravitasi. Proses sedimentasi pada pengolahan air limbah umumnya untuk menghilangkan padatan tersuspensi sebelum dilakukan proses pengolahan selanjutnya. Pada awalnya, gumpalan padatan yang terbentuk pada proses koagulasi masih berukuran kecil. Gumpalangumpalan kecil ini akan terus saling bergabung menjadi gumpalan yang lebih besar dalam proses flokulasi. Dengan terbentuknya gumpalan-gumpalan besar, maka beratnya akan bertambah, sehingga karena gaya beratnya gumpalan-gumpalan tersebut akan bergerak ke bawah dan mengendap pada bagian dasar tangki sedimentasi.

Bak sedimentasi dapat berbentuk segi empat atau lingkaran. Pada bak ini aliran air limbah sangat tenang untuk memberi kesempatan padatan atau suspensi untuk mengendap. Kriteria-kriteria yang diperlukan untuk menentukan ukuran bak sedimentasi adalah surface loading (beban permukaan), kedalaman bak dan waktu tinggal. Waktu tinggal mempunyai satuan jam, cara perhitungannya adalah volume tangki dibagi dengan laju alir per hari. Beban permukaan sama dengan laju alir (debit volume) rata-rata per hari dibagi luas permukaan bak, satuannya $\mathrm{m}^{3}$ per $\mathrm{m}^{2}$ per hari.

$$
V_{0}=\frac{Q}{A}
$$


$V_{0}=$ laju beban permukaan $\left(\mathrm{m}^{3} / \mathrm{m}^{2}\right.$ hari)

$\mathrm{Q}=$ aliran rata-rata harian, $\left(\mathrm{m}^{3} /\right.$ hari $)$

$A=$ total luas permukaan $\left(\mathrm{m}^{2}\right)$

Untuk keamanan proses, maka waktu tinggal pengendapan dibuat dalam waktu 1 jam dan bak dibuat dengan bentuk silinder yang bagian bawahnya berupa kerucut. Dengan demikian maka volume bak yang diperlukan $2,5 \mathrm{~m}^{3} / \mathrm{jam} \times 1$ jam $=2,5 \mathrm{~m}^{3}$. Disain yang ada :

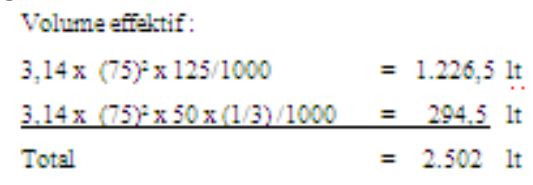

Volume effieltif:

$3,14 \times(75)^{2} \times 125 / 1000 \quad=1.226,51 \mathrm{lt}$

$\underline{3.14 \times(75): \times 50 \times(1 / 3) / 1000=294.5} \mathrm{lt}$

Total $=2.502 \mathrm{lt}$

Waltu tingal ttl $\quad=1.502 / 2.500=1 \mathrm{jam}$.
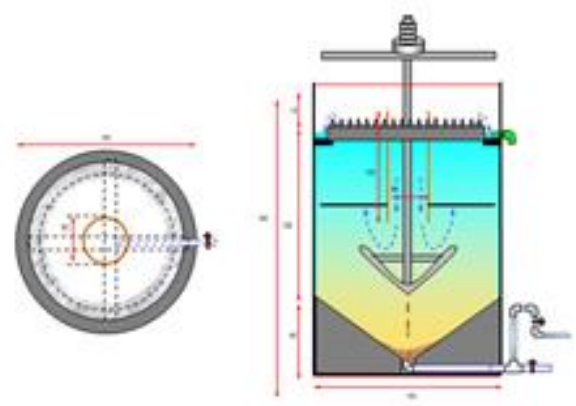

Gambar 13. Gambar Desain Bak Sedimentasi.

\subsubsection{Pengeringan Lumpur}

Lumpur yang dihasilkan dari proses sedimentasi diolah lebih lanjut untuk mengurangi sebanyak mungkin air yang masih terkandung didalamnya. Proses pengolahan lumpur yang bertujuan mengurangi kadar air tersebut sering disebut dengan pengeringan lumpur. Pengeringan lumpur dilakukan secara alamiah, yaitu dengan mengalirkan endapan lumpur ke bak pengering (sludge drying bed) yang didisain dengan cara meniris kandungan air kemudian lumpur yang tertahan di bak ini dikeringkan secara alami. Karena proses pengeringan membutuhkan waktu beberapa hari, maka bak ini dibuat dua buah dan dioperasikan secara bergantian. Gambar disain bak pengering lumpur ini adalah sebagai berikut :

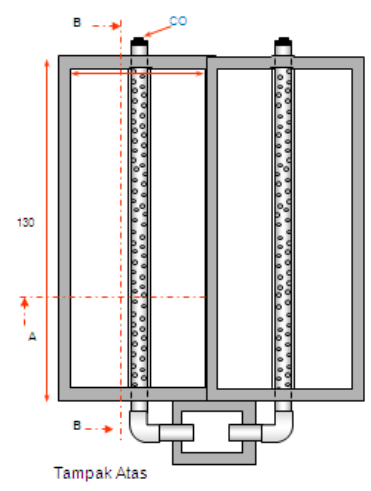

Gambar 14. Tampak Atas Bak Pengering Lumpur.
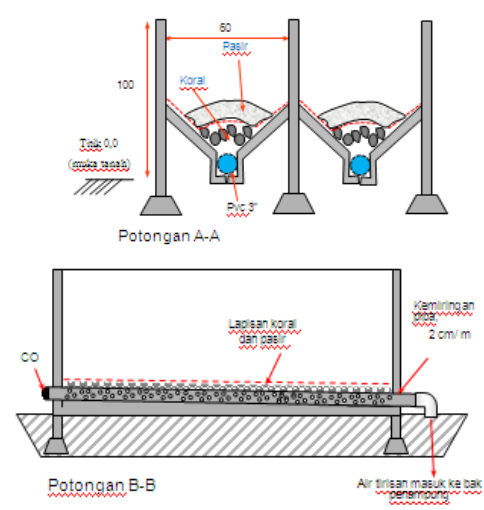

Gambar 15. Potongan A-A dan B-B Bak Pengering Lumpur.

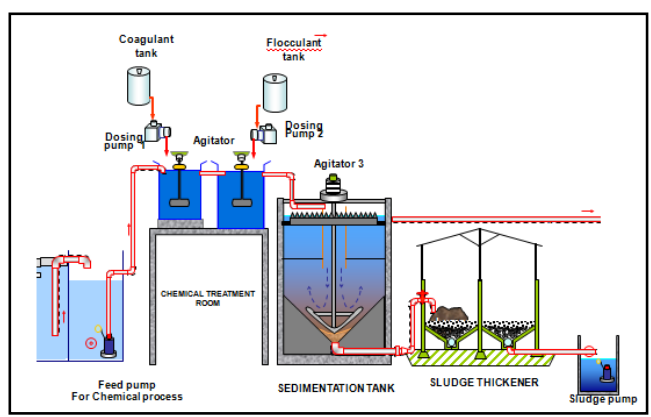

Gambar 16. Diagram Proses Pengolahank-Flokulasi Dan Sedimentasi

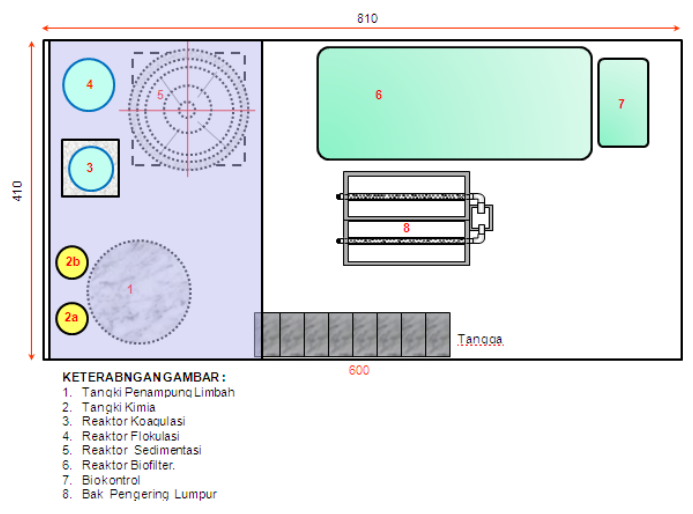

Gambar 17. Layout Unit Pre-Treatment

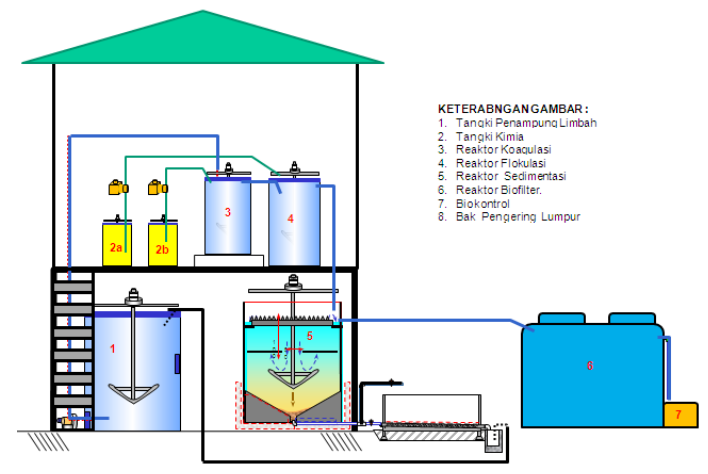

Gambar 18. Tampak Depan Unit Pre-Treatment. 


\subsubsection{Jenis Peralatan Elektrikal dan Konsumsi Listrik}

Jenis peralatan mekanikal dan elektrikal yang ada adalah, pompa, agotator dan pompa dosing. Jenis peralatan dan konsumsi power listrik yang diperlukan dapat dilihat seperti pada tabel 5 berikut.

Tabel 5. Jenis Peralatan Dan Kebutuhan Energi Listrik di IPAL

\begin{tabular}{|c|l|c|c|}
\hline No & \multicolumn{1}{|c|}{ Jenis Peralatan } & $\begin{array}{c}\text { Jumlah } \\
\text { (Unit) }\end{array}$ & $\begin{array}{c}\text { Daya } \\
\text { (Watt) }\end{array}$ \\
\hline 1 & Pompa pengumpul limbah produksi & 1 & 300 \\
\hline 2 & Pompa feed & 1 & 250 \\
\hline 3 & Pompa sirkulasi air limbah & 1 & 250 \\
\hline 4 & $\begin{array}{l}\text { Pompa dosing bahan kimia } \\
\text { (koagulant \& flokulant) }\end{array}$ & 2 & 50 \\
\hline 5 & $\begin{array}{l}\text { Agitator reaktor koagulasi \& } \\
\text { reaktor flokulasi }\end{array}$ & 2 & 90 \\
\hline 6 & Agitator bak pengendap & 1 & 250 \\
\hline 7 & Lampu penerangan & 4 & 40 \\
\hline \multicolumn{2}{|c|}{ Total konsumsi listrik } & 1.230 \\
\hline
\end{tabular}

Untuk mengoperasikan peralatan dan mesin yang ada, diperlukan satu panel yang dapat mengoperasikan dan mengontrol peralatan yang ada dari satu tempat. Peralatan ini disebut panel kontrol. Adapun panel listrik ditempatkan pada rumah panel yang menempel dengan dinding bangunan. Diagram kelistrikan untuk unit ini dapat dilihat seperti pada gambar 19.

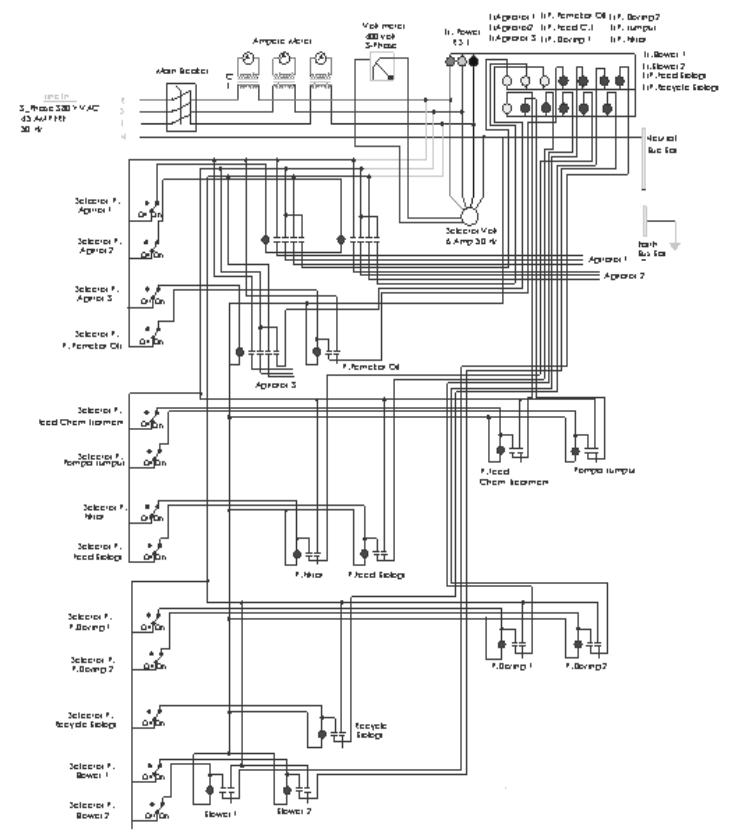

Gambar 19. Diagram alir kelistrikan IPAL

\subsubsection{Konsumsi Bahan Kimia dan Biayanya}

Berdasarkan hasil jar test, kebutuhan biaya bahan kimia untuk proses koagulasi-flokuasi sebesar Rp. $30.750,00 / \mathrm{m}^{3}$ limbah yang diolah. Jika faktor keamanan diambil sebesar $20 \%$, maka perkiraan biaya bahan kimia untuk operasional pengolahan limbah PT. Shei Tai Industrial sebesar Rp. $36.900,00 / \mathrm{m}^{3}$ limbah.

Tabel 6. Konsumsi dan Biaya Bahan Kimia.

\begin{tabular}{|c|c|c|c|c|}
\hline Chemical & $\begin{array}{l}\text { Dosis, } \\
\mathrm{ppm}\end{array}$ & $\begin{array}{c}\text { Konsumsi, } \\
\mathrm{Kg} / \mathrm{m}^{3}\end{array}$ & $\begin{array}{l}\text { Harga, } \\
\mathrm{Rp} . / \mathrm{Kg} \\
\end{array}$ & $\begin{array}{c}\text { Cost, } \\
\mathrm{Rp} . / \mathrm{m}^{3} \\
\end{array}$ \\
\hline Koagulan MN 7033 & $1.000,0$ & & 30.000 & 30.000 \\
\hline Flokulan MN 3200 & 2,5 & & 300.000 & 750 \\
\hline Asam/ basa & $\begin{array}{r}\text { Tergantung } \\
\text { kondisi }\end{array}$ & $\begin{array}{c}\text { Tergantung } \\
\text { kondisi }\end{array}$ & - & - \\
\hline \multicolumn{4}{|c|}{ Total kebutuhan biaya bahan kimia } & 30.750 \\
\hline
\end{tabular}

\section{KESIMPULAN}

\subsection{Kesimpulan}

1) Limbah produksi PT. Shei Tai Industrial banyak mengandung oli dan bahan kimia tersuspensi maupun terlarut.

2) Berdasarkan hasil evaluasi dan analisa hasil percobaan, maka teknologi pre-treatment ini dapat dilakukan dengan proses fisiki-kimia, yaitu dengan proses penyaringan padatan, pemisahan oli, koagulasi - flokulasi dan diakhiri dengan proses pengendapan.

3) Meski telah melakukan pre-treatment limbah produksinya, tetapi limbah padat yang dihasilkan dari proses pre-treatment ini tetap harus dikirim ke pengelola limbah B3.

\subsection{Saran}

1) Untuk memantau kualitas limbah buangannya, sebaiknya setelah unit pre-treatment ini dibangun dilengkapi dengan sarana quality control outlet limbah.

2) Calon operator unit ini sebaiknya diberikan pelatihan-pelatihan yang cukup.

\section{DAFTAR PUSTAKA}

- Pengelola Kawasan MM 2100, "Data standar Kualitas Air Limbah \& Air Industri Kawasan MM 2100".

- Envirotekno Karya Mandiri "Laporan Analisis, Evaluasi dan Perencanaan Pengelolaan Limbah PT. Shei Tai Industrial" 2014.

- Standar kualitas air limbah industri wilayah Jawa Barat berdasarkan Pergub Jawa Barat No. 6/1999, tanggal 13 Maret 1999.

- Setiyono, (2014). "Kawasaki Motor Green Industri". BPPT Press, 2014.

- Setiyono, Satmoko Yudo "Panduan Pengelolaan Instalasi Pengolahan Air Limbah Industri Otomotif" BPPT Press 2014. 